\title{
A Modeling and Experimental Study on the Growth of VCSEL Materials Using an $8 \times 6$ Inch Planetary MOCVD Reactor
}

\author{
Yudan Gou ${ }^{1,2,3}$, Jun Wang ${ }^{1,2,3, *}$, Yang Cheng ${ }^{3}$, Yintao Guo ${ }^{3}$, Xiao Xiao ${ }^{3}$ and Shouhuan Zhou ${ }^{1}$ \\ 1 College of Electronics and Information Engineering, Sichuan University, Chengdu 610065, China; \\ gouyudan@stu.scu.edu.cn (Y.G.); zhoush@scu.edu.cn (S.Z.) \\ 2 Key Laboratory of Wireless Power Transmission of Ministry of Education, Sichuan University, \\ Chengdu 610065, China \\ 3 Suzhou Everbright Photonics Co., Ltd., Suzhou 215000, China; yang.cheng@everbrightphotonics.com (Y.C.); \\ yintao.guo@everbrightphotonics.com (Y.G.); xiao.xiao@everbrightphotonics.com (X.X.) \\ * Correspondence: wjdz@scu.edu.cn
}

Received: 17 July 2020; Accepted: 13 August 2020; Published: 18 August 2020

\begin{abstract}
VCSEL (vertical cavity surface emitting laser) is a promising optoelectronic device, but its high manufacturing cost limits its scope of applications. Growing on larger size wafers is an effective way to reduce the cost. However, the growth rate uniformity needs to be optimized to ensure the uniformity of the devices' performance over the wafers. This paper investigates the factors which influence the growth rate uniformity using an $8 \times 6$ inch planetary reactor through experiments and simulations. At a carrier gas flow rate of $37 \mathrm{slm}$, an $\mathrm{AsH}_{3}$ flow rate of $600 \mathrm{sccm}$, an $\mathrm{AsH}_{3}$ flow rate ratio of 100:500, and a ceiling temperature of $175^{\circ} \mathrm{C}$, the growth rate uniformity of the AlGaAs layer with a relative standard deviation of $0.16 \%, 1 \sigma$, was obtained over the 6 -inch wafers. The uniformity of the DBR stop band center and VCSEL quantum well wavelength with standard deviations of $0.142 \%$ and $0.023 \%, 1 \sigma$, were received over the 6 -inch wafers, respectively. Based on the optimized results, $99.95 \%$ of VCSEL devices with wavelengths of $940 \pm 5 \mathrm{~nm}$ were realized over the 6-inch wafers.
\end{abstract}

Keywords: metalorganic chemical vapor deposition; vertical cavity surface emitting laser; growth models; growth rate uniformity

\section{Introduction}

The development of metal-organic chemical vapor deposition (MOCVD) technology has contributed to improving the performance of the optoelectronic devices, such as the edge emitting laser (EEL) [1,2], vertical-cavity surface-emitting laser (VCSEL) [3,4], and photovoltaic cell (PVC) [5,6]. However, the cost of epitaxy is still too high for many applications. Enlarging the MOCVD chamber and using larger wafers are the possible approaches to deal with the problem. In the past decade, many large chamber reactor designs have been developed, including the close-coupled showerhead (CCS) [7-9], the high speed rotating disk reactor (RDR) [10,11], and the planetary reactor [12]. Compared to the other two, the planetary reactor has attracted more attention due to its higher material utilization. However, as a type of horizontal reactor [13], it is difficult to control the depletion profile and premature reactions. One of the current planetary MOCVD configurations introduces an injector design which has two flow channels to separately supply group III and V precursors to prevent premature reactions. MO-precursors are injected through the top channel with the carrier gas, and hydrides along with carrier gas are injected through the bottom channel. When the size of the reactor chamber is further expanded to facilitate higher wafer capacity, more precise control of the depletion profile is required. The hydride gas flowing through the bottom channel acts as an impedance to the growth nutrients that 
diffuse to the wafer surface due to its density and momentum, resulting in poor utilization efficiency of MO-precursors [14]. To solve this problem, a new planetary MOCVD with a third gas inlet above the MO injector channel was designed to supply hydride species, which is shown schematically in Figure 1. The third channel provides more control over the peak position of the depletion profile, resulting in higher reactant utilization efficiency. Furthermore, the ratio of the hydride gas flow rates is a tuning parameter for the growth rate uniformity [15].

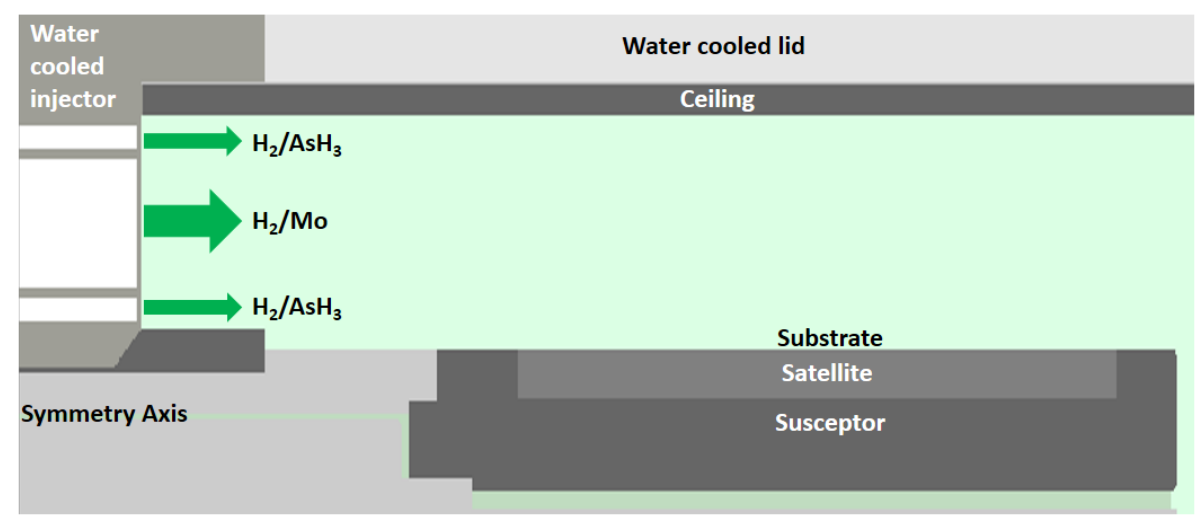

Figure 1. Schematic for planetary reactor chamber with a three-flow gas injector.

VCSEL has recently become a hot spot due to its excellent photoelectric characteristics. The $8 \times 6$ inch planetary reactor with triple flow technology is used for mass production. However, in [12], a growth rate uniformity with a standard deviation of $0.86 \%$ was obtained using this reactor, which cannot meet the needs of the growth rate uniformity for VCSEL materials. The VCSEL structure contains 20 and $40 \mathrm{Al}_{0.9} \mathrm{GaAs} / \mathrm{Al}_{0.6} \mathrm{GaAs}$ DBR (Distributed Bragg Reflector) periods for $\mathrm{p}$-side and n-side, respectively. The thickness uniformity of DBR determines the uniformity of the device's performance over the 6-inch wafer. Therefore, it is important to optimize the growth rate uniformity to ensure a uniform DBR thickness.

In this study, the process of tuning the $8 \times 6$ inch planetary reactor for growth rate uniformity was investigated by experiments and simulations, including carrier gas flow rate, total $\mathrm{AsH}_{3}$ flow rate, $\mathrm{AsH}_{3}$ flow rate ratio, and ceiling temperature. The growth rate uniformity of the AlGaAs layer with a relative standard deviation of $0.16 \%, 1 \sigma$, was received over the 6 -inch wafers, and the distribution uniformity of DBR stop-band center and quantum well wavelength with standard deviations of $0.142 \%$ and $0.023 \%, 1 \sigma$, were obtained over the 6-inch wafers, respectively. Furthermore, the VCSEL devices using the optimized conditions exhibited uniform wavelength over the 6-inch wafers.

\section{Model}

Simulations were performed using CVDSim software [16]. Gas-phase and surface chemical reaction kinetics; conductivity; fluid dynamics; radiative and convective heat exchange; thermal diffusion; and multi-component species diffusion are included in the model. In the simulation model, the gas mixture was assumed to be ideal gas, and fluid flow was assumed to be laminar and incompressible. Trimethylgallium (TMGa) and trimethylaluminium (TMAl) were used as group-III sources, arsine $\left(\mathrm{AsH}_{3}\right)$ was used as hydride gas, and hydrogen was used as the carrier gas to deliver the MO-precursors. The species abbreviations are listed in Table 1. 
Table 1. Abbreviation of species.

\begin{tabular}{cc}
\hline Chemical Formula & Abbreviation \\
\hline $\mathrm{Ga}(\mathrm{CH} 3)_{3}$ & TMGa \\
$\mathrm{Al}(\mathrm{CH})_{3}$ & TMAl \\
$\mathrm{GaCH}_{3}$ & $\mathrm{MMGa}$ \\
$\mathrm{AlCH}_{3}$ & $\mathrm{MMAl}$ \\
\hline
\end{tabular}

The AlGaAs reaction kinetics consist of gas phase reactions and surface reactions. The gas phase chemistry is mainly dominated by thermal decomposition of the group-III MO-precursors [17] and the first-order decomposition reactions of MO-precursors, and the details of gas phase kinetics for AlGaAs material are presented in Table 2. Surface reactions occur near the wafer surface and determine the growth rate uniformity [7]; the surface reaction pathways of AlGaAs are listed in Table 3. Within the quasi-thermodynamic model of the surface chemistry [18], any arbitrary set of independent reactions can be considered. The reaction rates were computed from the thermo-chemical properties of species and solids involved. Figure 2 illustrates the mass fluxes of group-III species over the 6-inch wafers. It reveals that the major contributions to the AlGaAs growth process are provided by TMGa, MMGa, and TMAl.

Table 2. Gas-phase $(\mathrm{G})$ reaction pathways and kinetic parameters for AlGaAs growth.

\begin{tabular}{ccccc}
\hline & Gas-Phase Reactions & $\boldsymbol{A}\left(\mathbf{s}^{\mathbf{- 1}}\right)$ & $\boldsymbol{E}(\mathbf{k c a l} / \mathbf{m o l})$ & Ref. \\
\hline G1 & TMGa -> MMGa $+2 \mathrm{CH}_{3}{ }^{*}$ & $3.47 \times 10^{15}$ & 59.5 & {$[18]$} \\
G2 & TMAl -> MMAl + $2 \mathrm{CH}_{3}{ }^{*}$ & $3.47 \times 10^{15}$ & 66.0 & {$[18]$} \\
\hline
\end{tabular}

Note: reaction rate constant $k=A \exp (-E / R T)$, where $A$ is the pre-exponential factor and $E$ is the activation energy.

Table 3. Surface $(\mathrm{S})$ reaction pathways for AlGaAs growth.

\begin{tabular}{ccc}
\hline & Surface Reactions & Ref. \\
\hline S1 & $\mathrm{TMGa}+\mathrm{AsH}_{3}<->\mathrm{GaAs}(\mathrm{s})+3 \mathrm{CH}_{4}$ & {$[18,19]$} \\
$\mathrm{S} 2$ & $\mathrm{TMAl}+\mathrm{AsH}_{3}<->\mathrm{AlAs}(\mathrm{s})+3 \mathrm{CH}_{4}$ & {$[18]$} \\
S3 & $\mathrm{MMGa}+\mathrm{AsH}_{3}<->\mathrm{GaAs}(\mathrm{s})+\mathrm{CH}_{4}+\mathrm{H}_{2}$ & {$[18,19]$} \\
$\mathrm{S} 4$ & $\mathrm{MMAl}+\mathrm{AsH}_{3}<->\mathrm{AlAs}(\mathrm{s})+\mathrm{CH}_{4}+\mathrm{H}_{2}$ & {$[18]$} \\
S5 & $2 \mathrm{AsH}_{3}<->\mathrm{As}_{2}+3 \mathrm{H}_{2}$ & {$[18,19]$} \\
S6 & $4 \mathrm{AsH}_{3}<->\mathrm{As}_{4}+6 \mathrm{H}_{2}$ & {$[18,19]$} \\
S7 & $2 \mathrm{CH}_{3}+\mathrm{H}_{2}<->2 \mathrm{CH}_{4}$ & {$[18,19]$} \\
\hline
\end{tabular}

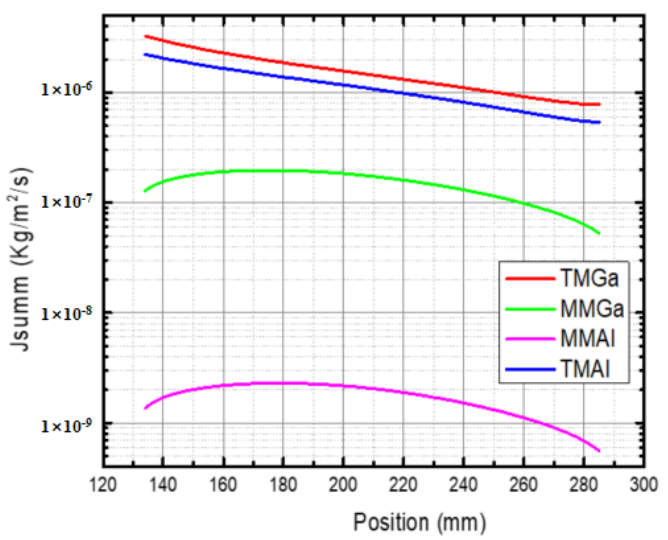

Figure 2. Simulated results of the mass fluxes of the AlGaAs materials along the susceptor radius r. Gases inlet at reactor chamber centre $(\mathrm{r}=0 \mathrm{~mm})$, and the substrate located at $134 \mathrm{~nm}$ to $285 \mathrm{~nm}$. $\mathrm{P}=5 \times 10^{3} \mathrm{~Pa}, \mathrm{~T}_{\text {growth }}=700{ }^{\circ} \mathrm{C}$, total $\mathrm{AsH}_{3}$ flow rate $\mathrm{Q}_{\mathrm{AsH} 3}=600 \mathrm{sccm}$, carrier gas flow rate $\mathrm{Q}_{\mathrm{H} 2}=37 \mathrm{slm}$. 


\section{Experimental}

The $8 \times 6$ inch Planetary Reactor was used in this study. The wafers were placed on the satellites symmetrically around the reactor center. A triple-flow gas injector was employed to supply nutrient species in a circularly symmetric manner. The MO-precursors with carrier gas were injected through the central gas inlet, and the hydrides with carrier gas were injected through the top and bottom channels. The temperature of the reactor ceiling was tuned by the ratio of hydrogen and nitrogen flow rates, which were injected through the narrow gap between the ceiling and the water-cooled reactor lid.

In order to optimize the growth rate uniformity of the AlGaAs layer, the growth rate profiles on the rotating and static wafers were investigated by the thickness of the layer across the 6-inch wafers. The layer thicknesses were measured by triple-crystal X-ray diffractometry (XRD). The DBR stop-band center distribution map and VCSEL quantum well wavelength distribution map were measured by photoluminescence (PL). The VCSEL device characteristics were measured by probing station made by Chroma, model 58635.

\section{Results and Discussion}

\subsection{Growth Rate Uniformity}

The growth rate uniformity is defined by the relative standard deviation over the rotating substrate [7]:

$$
\begin{gathered}
\overline{G R}=\sum_{i=1}^{n} G R_{i} \times \frac{S_{i}}{S} \\
\Delta=\frac{\sqrt{\sum_{i=1}^{n}\left(G R_{i}-\overline{G R}\right)^{2} \times \frac{S_{i}}{S}}}{\overline{G R}}
\end{gathered}
$$

where $\overline{G R}$ and $\Delta$ represent the average growth rate and the growth rate uniformity, respectively. $G R_{i}$ is the growth rate of the $i_{t h}$ location of the substrate. $S_{i}$ and $S$ represent the area of the $i_{t h}$ location and the total area of the substrate, respectively.

As shown in Figure 3a-I, the static growth rates show linearly declining profiles along the wafer diameter due to the depletion of MO-precursor species. At higher carrier gas flow rate, the depletion of MO-precursors' decomposition by-products is pushed further downstream, and thus, the slope of the static depletion profile decreases. Uniform growth rates are obtained by rotating the individual substrates. As shown in Figure 3a-II, with the carrier gas flow rate increased from 24 to $37 \mathrm{slm}$, the experimental growth rate uniformity changes from $1.06 \%$ to $0.16 \%$, and the simulation results decrease from $0.79 \%$ to $0.15 \%$. These results indicate good predictability of the simulation model. Numerical modeling allows for speedy optimization the growth rate uniformity under complex process conditions. As shown in Figure 3b, the growth rate uniformity changes from $0.79 \%$ to $0.13 \%$ with the carrier gas flow rate increased from 24 to $44 \mathrm{slm}$. Based on the balance of the growth rate uniformity and the cost of the source materials, a growth rate of $2.95 \mu \mathrm{m} / \mathrm{h}$ with uniformity of $0.16 \%$ at carrier gas flow rate of $37 \mathrm{slm}$ was selected in this study.

The hydride flow rate is another important tuning factor to further optimize the growth rate uniformity. Figure 4 shows the effects of total $\mathrm{AsH}_{3}$ flow rate on growth rate and its uniformity. By increasing the total $\mathrm{AsH}_{3}$ flow rate from 400 to $800 \mathrm{sccm}$, the growth rate decreases from 2.97 to $2.93 \mu \mathrm{m} / \mathrm{h}$ and the growth rate uniformity changes from $0.29 \%$ to $0.15 \%, 1 \sigma$. The best growth rate uniformity can be obtained at the total $\mathrm{AsH}_{3}$ flow rate around $600 \mathrm{sccm}$. 

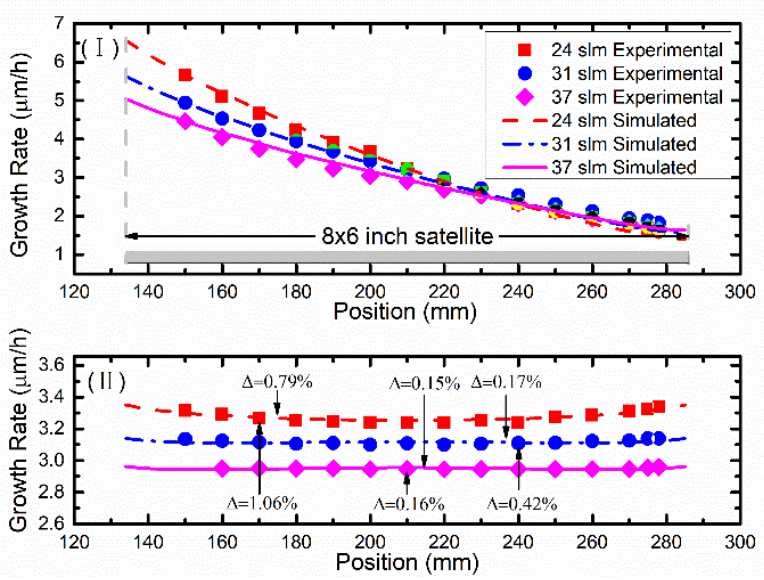

(a)

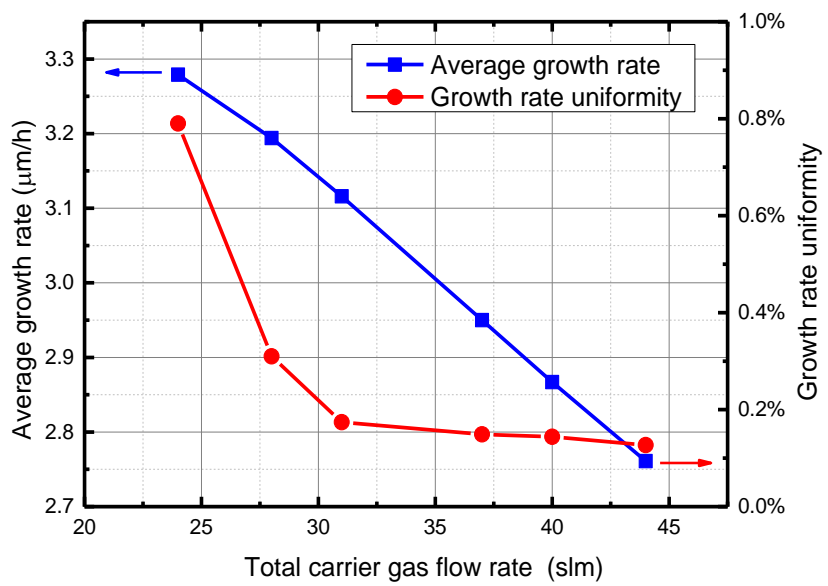

(b)

Figure 3. (a) Experimental and simulated results of AlGaAs growth rate profiles for various carrier gas flow rates as functions of the susceptor radius $\mathrm{r}(\mathrm{r}=0 \mathrm{~mm}$ for gas inlet at reactor chamber center). (I) Depletion profiles of the static substrates. (II) Growth rate profiles of the rotating substrates. Values for growth rate uniformity are included. (b) Simulation results of average growth rate and growth rate uniformity for various carrier gas flow rates on rotating satellites. $\mathrm{P}=5 \times 10^{3} \mathrm{~Pa}$, $\mathrm{T}_{\text {growth }}=700^{\circ} \mathrm{C}$, total $\mathrm{AsH}_{3}$ flow rate $\mathrm{Q}_{\mathrm{AsH} 3}=600 \mathrm{sccm}$.

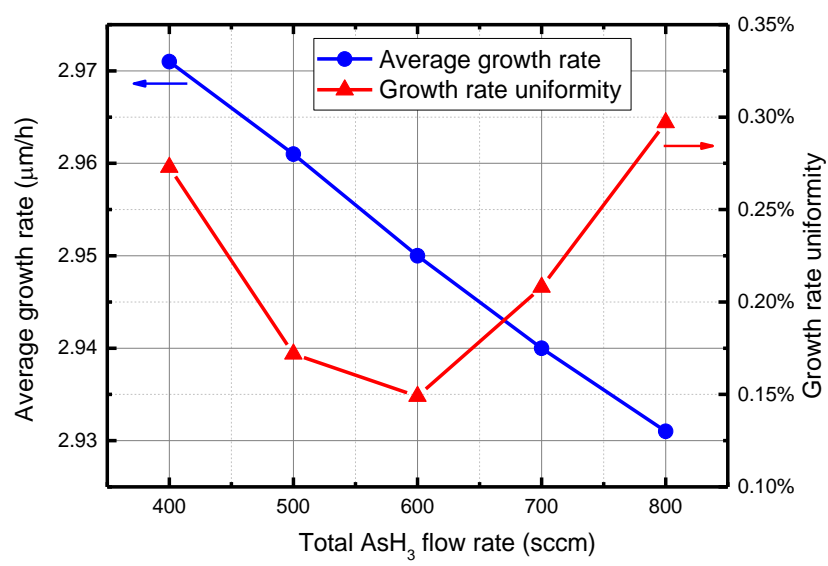

Figure 4. Simulated results of the average growth rate and growth rate uniformity as functions of the total $\mathrm{AsH}_{3}$ flow rate. $\mathrm{P}=5 \times 10^{3} \mathrm{~Pa}, \mathrm{~T}_{\text {growth }}=700^{\circ} \mathrm{C}$, carrier gas flow rate $\mathrm{Q}_{\mathrm{H} 2}=37 \mathrm{slm}$. 
As the triple-flow injector technology was applied in the $8 \times 6$ inch planetary reactor, the ratio of the $\mathrm{AsH}_{3}$ flow rate through the top and bottom channels could be used as a tuning parameter for the growth rate uniformity, which was realized by optimizing the depletion profile with respect to the upstream leading wafer edge position [12]. Figure 5 shows the effects of the $\mathrm{AsH}_{3}$ ratio on the static and rotating growth rate profiles. It reveals that at higher top $\mathrm{AsH}_{3}$ flow rates, higher growth rate values are obtained at the upstream end of the static curve, which is close to the reactor center since the higher top $\mathrm{AsH}_{3}$ flow rate shortens the nutrient species entrance length [14]. As shown in Figure 6, higher top $\mathrm{AsH}_{3}$ flow rate improves the concentration of TMGa near the leading wafer edge. With the $\mathrm{AsH}_{3}$ flow rate ratio varying from 500:100 to 100:500, the growth rate uniformity changes from $1.34 \%$ to $0.15 \%, 1 \sigma$. Therefore, an $\mathrm{AsH}_{3}$ flow rate ratio of 100:500 was selected in this study.

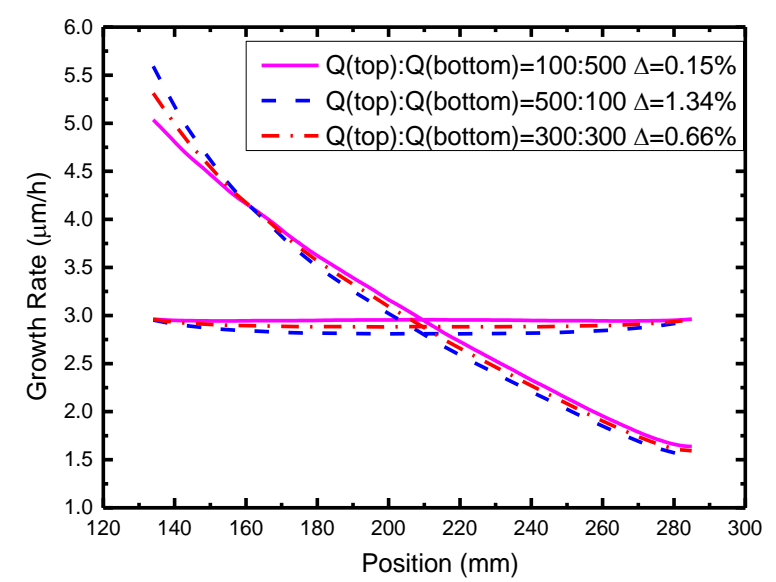

Figure 5. Simulated results of the growth rate profiles for the various top to bottom $\mathrm{AsH}_{3}$ ratios as functions of satellite radius. $\mathrm{P}=5 \times 10^{3} \mathrm{~Pa}, \mathrm{~T}_{\text {growth }}=70{ }^{\circ} \mathrm{C}$, carrier gas flow rate $\mathrm{Q}_{\mathrm{H} 2}=37 \mathrm{slm}$, total $\mathrm{AsH}_{3}$ flow rate $\mathrm{Q}_{\mathrm{AsH} 3}=600 \mathrm{sccm}$.

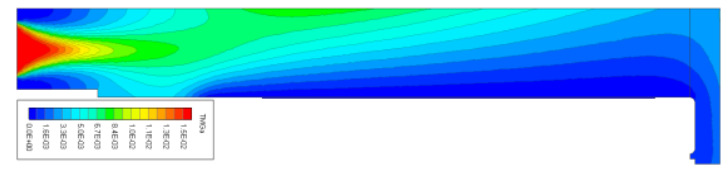

(a)

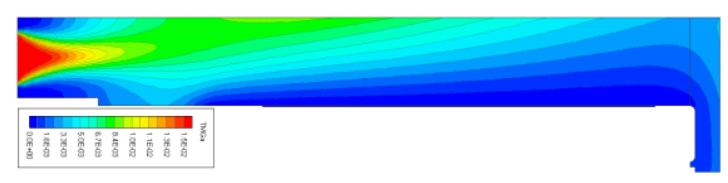

(b)

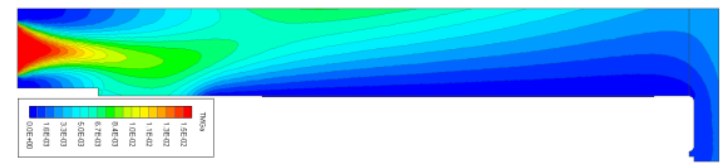

(c)

Figure 6. Two-dimensional distribution of TMGa in the reactor chamber for various top to bottom $\mathrm{AsH}_{3}$ ratios: (a) 300:300; (b) 100:500; (c) 500:100.

As shown in Figure 7, the temperature of the ceiling affects the growth rate, growth rate uniformity, and $\mathrm{AlGaAs}$ deposition rates on the ceiling. The ceiling temperature is tuned by the ratio of nitrogen 
and hydrogen $\left(\mathrm{N}_{2} / \mathrm{H}_{2}\right)$. The $\mathrm{N}_{2} / \mathrm{H}_{2}$ mixture gas injects through the narrow gap between the ceiling and the water-cooled reactor lid. By tuning the ratio of the mixture gas, an optimal ceiling temperature with good growth rate uniformity can be selected. The ceiling temperature affects the temperature distribution along the horizontal and vertical substrate axis [12]. As Figure 7 illustrates, a poor growth rate uniformity was obtained at a lower ceiling temperature due to the arsenic-containing species condensing on the ceiling under such conditions, resulting in poor temperature uniformity over the substrates [20]. With the ceiling temperature increased from 66 to $188^{\circ} \mathrm{C}$, the growth rate increased from 2.76 to $2.96 \mu \mathrm{m} / \mathrm{h}$, and the growth rate uniformity changed from 0.16 to $0.15 \%$. However, with the ceiling temperature increased, the deposition rate of AlGaAs on the ceiling increased, resulting in a shortened ceiling lifetime [21]. With the ceiling temperature increased from 66 to $188^{\circ} \mathrm{C}$, the deposition rate of $\mathrm{AlGaAs}$ increased from 0.017 to $0.028 \mu \mathrm{m} / \mathrm{h}$. Based on the above results, a ceiling temperature around $175^{\circ} \mathrm{C}$ was selected in this study. Under said condition, arsenic-containing species were not easily condensed on the ceiling, and the AlGaAs deposition rate was slow enough, so a good growth rate uniformity was obtained on the 6-inch wafers.

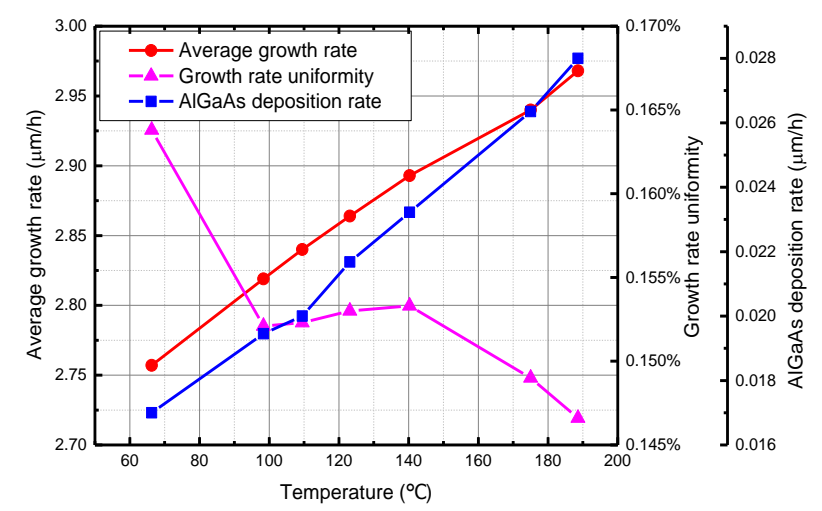

Figure 7. Simulated results of average growth rate, growth rate uniformity, and AlGaAs deposition rates as functions of ceiling temperature; the $\mathrm{AlGaAs}$ deposition rates and ceiling temperature were measured at a radial position of $210 \mathrm{~mm}$ from the chamber center. $\mathrm{P}=5 \times 10^{3} \mathrm{~Pa}, \mathrm{~T}_{\text {growth }}=700{ }^{\circ} \mathrm{C}$, carrier gas flow rate $\mathrm{Q}_{\mathrm{H} 2}=37 \mathrm{slm}$, total $\mathrm{AsH}_{3}$ flow rate $\mathrm{Q}_{\mathrm{AsH} 3}=600 \mathrm{sccm}$.

\subsection{Performance of VCSEL}

Based on the process optimized results, a VCSEL structure was grown using an $8 \times 6$ inch planetary reactor. Figure 8 shows the measured results of the reflection of a VCSEL structure, which was measured by IR spectrophotometer. The stop-band reflection was near $99.9 \%$. It revealed a good growth rate uniformity of DBR.

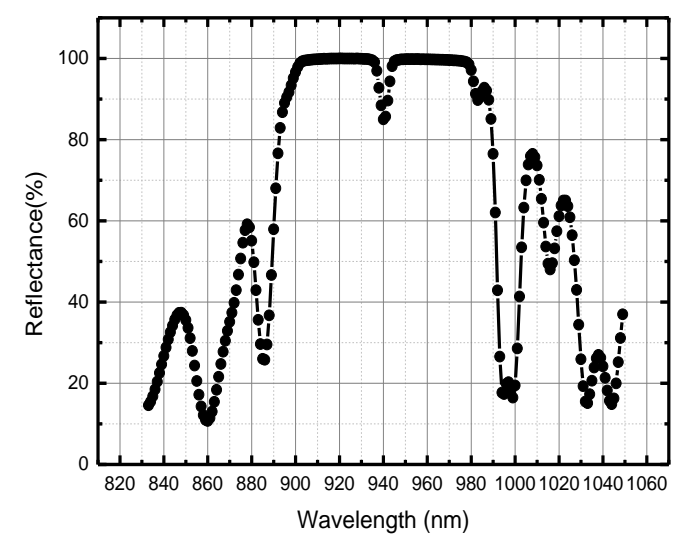

Figure 8. Measured results of the reflectance of a VCSEL (vertical cavity surface emitting laser) structure as functions of wavelength. 
Figure 9 shows the DBR stop-band center and quantum well wavelength distribution map over the 6-inch wafers, which was measured by photoluminescence (PL). The distribution uniformity of DBR stop-band center and the VCSEL quantum well wavelength with standard deviations of $0.142 \%$ and $0.023 \%, 1 \sigma$, were obtained, respectively.

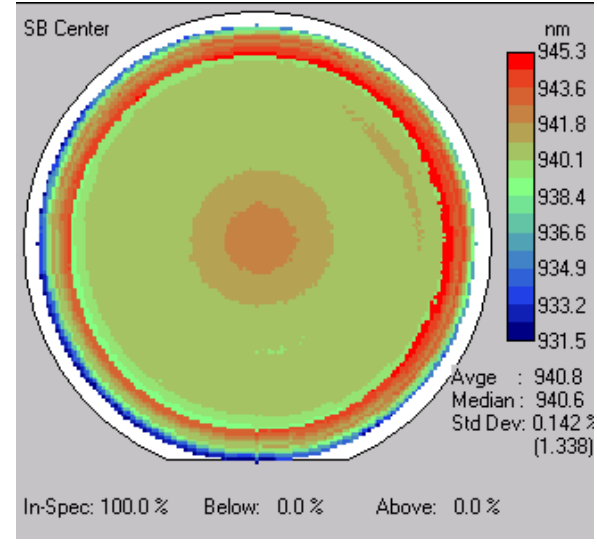

(a)

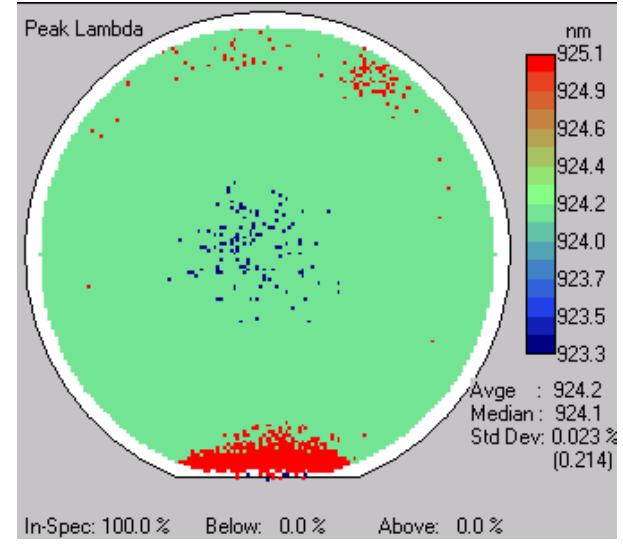

(b)

Figure 9. Distribution map of (a) DBR (Distributed Bragg Reflector) stop-band center and (b) quantum well wavelength over the 6-inch wafer ( $5 \mathrm{~mm}$ edge exclusion).

Figure 10 shows that $99.95 \%$ of VCSEL devices with wavelengths of $940 \pm 5 \mathrm{~nm}$ were realized over the 6-inch wafers, which was measured by a probing station made by Chroma (model 58635). That indicates that a good growth rate uniformity of VCSEL materials was achieved in the $8 \times 6$ inch planetary reactor.

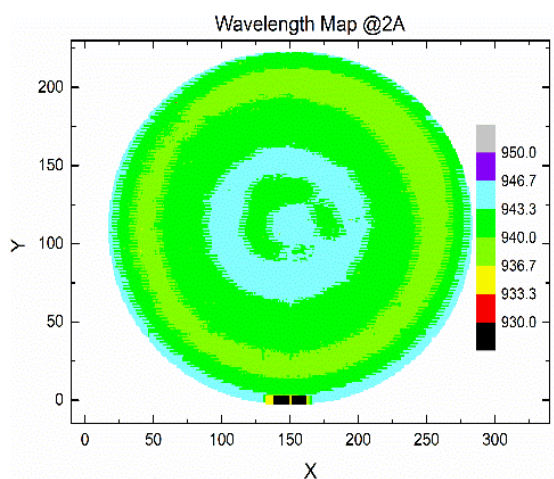

(a)

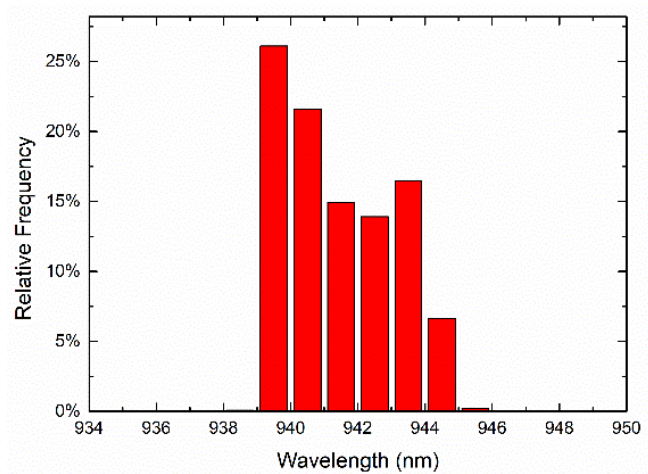

(b)

Figure 10. Performance of VCSEL devices over the 6-inch wafer measured by probing station made by Chroma (model) at 2A: (a) wavelength distribution map, (b) frequency statistics of wavelength.

\section{Conclusions}

To meet the demands of the reducing manufacturing cost, the process optimization for growth rate uniformity in an $8 \times 6$ inch planetary reactor was investigated in this paper. It revealed that the growth rate uniformity is determined by the carrier gas flow rate, total $\mathrm{AsH}_{3}$ gas flow rate, $\mathrm{AsH}_{3}$ flow rate ratio, and ceiling temperature. The growth rate uniformity of the AlGaAs layer with a relative standard deviation of $0.16 \%, 1 \sigma$, was obtained over the 6-inch wafers. Based on the process optimized results, the distribution uniformity of DBR stop-band center and the VCSEL quantum well wavelength with standard deviations of $0.142 \%$ and $0.023 \%, 1 \sigma$, were achieved over the 6-inch wafers, respectively. Furthermore, $99.95 \%$ of VCSEL devices with wavelengths of $940 \pm 5 \mathrm{~nm}$ were realized over the 6-inch wafers, indicating a good growth rate uniformity during the growth process. 
Author Contributions: Conceptualization, Y.G. (Yudan Gou) and J.W.; methodology, Y.G. (Yudan Gou); software, Y.G. (Yudan Gou); validation, Y.C., and Y.G. (Yudan Gou); formal analysis, Y.G. (Yintao Guo); investigation, Y.G. (Yintao Guo), X.X., S.Z., and J.W.; resources, J.W.; data curation, Y.G. (Yudan Gou); writing-original draft preparation, Y.G. (Yudan Gou); writing-review and editing, J.W., Y.C., Y.G. (Yintao Guo), X.X., and S.Z.; visualization, Y.G. (Yudan Gou) and J.W.; supervision, J.W.; project administration, Y.G. (Yudan Gou) and J.W. All authors have read and agreed to the published version of the manuscript.

Funding: There is no funding support for this research.

Acknowledgments: The authors thank E. V. Yakovlev and M. S. Ramm from the STR Group and Martin Dauelsberg from AIXTRON SE for helpful discussions regarding this work.

Conflicts of Interest: The authors declare no conflict of interest.

\section{References}

1. Lu, Z.; Wang, L.; Zhao, Z.; Shu, S.; Hou, G.; Lu, H.; Tian, S.; Tong, C.; Wang, L. Broad-area laser diodes with on-chip combined angled cavity. Chin. Opt. Lett. 2017, 15, 081402.

2. Wang, T.; Wang, L.; Shu, S.; Tian, S.; Zhao, Z.; Tong, C.; Wang, L. Suppression of far-field blooming in high-power broad-area diode lasers by optimizing gain distribution. Chin. Opt. Lett. 2017, 15, 071404. [CrossRef]

3. Bao, L.; Kim, N.H.; Mawst, L.J.; Elkin, N.N.; Troshchieva, V.N.; Vysotsky, D.V.; Napartovich, A.P. Near-diffraction-limited coherent emission from large aperture antiguided vertical-cavity surface-emitting laser arrays. Appl. Phys. Lett. 2004, 84, 320-322. [CrossRef]

4. Mereuta, A.; Sirbu, A.; Caliman, A.; Suruceanu, G.; Iakovlev, V.; Mickvic, Z.; Kapon, E. Fabrication and performance of 1.3- $\mu \mathrm{m}$ 10-Gb/s CWDM wafer-fused VCSELs grown by MOVPE. J. Cryst. Growth. 2015, 414, 210-214. [CrossRef]

5. Yoon, J.; Jo, S.; Chun, I.S.; Jung, I.; Kim, H.-S.; Meitl, M.; Menard, E.; Li, X.; Coleman, J.J.; Paik, U.; et al. GaAs photovoltaics and optoelectronics using releasable multilayer epitaxial assemblies. Nature 2010, 465, 329-333. [CrossRef] [PubMed]

6. Kim, Y.; Shin, H.B.; Lee, W.H.; Jung, S.H.; Kim, C.Z.; Kim, H.; Lee, Y.T.; Kang, H.K. 1080 nm InGaAs laser power converters grown by MOCVD using InAlGaAs metamorphic buffer layers. Sol. Energy Mat. Sol. Cells 2019, 200, 109984. [CrossRef]

7. Zhang, Z.; Fang, H.S.; Yao, Q.X.; Yan, H.; Gan, Z.Y. Species transport and chemical reaction in a MOCVD reactor and their influence on the GaN growth uniformity. J. Cryst. Growth. 2016, 454, 87-95. [CrossRef]

8. Li, Z.; Jiao, T.; Hu, D.; Lv, Y.; Li, W.; Dong, X.; Zhang, B. Study on $\beta-G a 2 O 3$ Films Grown with Various VI/III Ratios by MOCVD. Coatings 2019, 9, 281. [CrossRef]

9. Hu, C.K.; Chen, C.J.; Wei, T.C.; Li, T.T.; Huang, C.Y.; Chao, C.L.; Lin, Y.J. Numerical verification of gallium nitride thin-film growth in a large MOCVD reactor. Coatings 2017, 7, 112. [CrossRef]

10. Su, J.; Armour, E.; Lee, S.M.; Arif, R.; Papasouliotis, G.D. Uniform growth of III-nitrides on $200 \mathrm{~mm}$ silicon substrates using a single wafer rotating disk MOCVD reactor. Phys. Status Solidi A. 2016, 213, 856-860. [CrossRef]

11. Kadinski, L.; Merai, V.; Parekh, A.; Ramer, J.; Armour, E.A.; Stall, R.; Gurary, A.; Galyukov, A.; Makarov, Y. Computational analysis of $\mathrm{GaN} / \mathrm{InGaN}$ deposition in MOCVD vertical rotating disk reactors. J. Cryst. Growth 2004, 261, 175-181. [CrossRef]

12. Schmitz, D.A.; Habermann, S.; Hofeldt, J.; Brien, D.; Schineller, B.; Heuken, M. Application of Advanced Planetary Reactor ${ }^{\circledR}$ Technology for Production of III-V Compound Semiconductor Materials for CPV on 6 "Ge Wafers. In Proceedings of the 37th IEEE Photovoltaic Specialists Conference, Seattle, WA, USA, 19-24 June 2011; pp. 000546-000551.

13. Black, L.R.; Clark, I.O.; Fox, B.A.; Jesser, W.A. MOCVD of GaAs in a horizontal reactor: Modeling and growth. J. Cryst. Growth 1991, 109, 241-245. [CrossRef]

14. Brien, D.; Dauelsberg, M.; Christiansen, K.; Hofeldt, J.; Deufel, M.; Heuken, M. Modelling and simulation of MOVPE of GaAs-based compound semiconductors in production scale Planetary Reactors. J. Cryst. Growth 2007, 303, 330-333. [CrossRef]

15. Martin, C.; Dauelsberg, M.; Protzmann, H.; Boyd, A.R.; Thrush, E.J.; Heuken, M.; Talalaev, R.A.; Yakovlev, E.V.; Kondratyev, A.V. Modelling of group-III nitride MOVPE in the closed coupled showerhead reactor and Planetary Reactor ${ }^{\circledR}$. J. Cryst. Growth 2007, 303, 318-322. [CrossRef] 
16. STR Group, Modeling of Crystal Growth and Devices. Available online: http://www.str-soft.com/ (accessed on 17 October 2019).

17. Parikh, R.P.; Adomaitis, R.A. An overview of gallium nitride growth chemistry and its effect on reactor design: Application to a planetary radial-flow CVD system. J. Cryst. Growth 2006, 286, 259-278. [CrossRef]

18. Yakovlev, E.V.; Shpolyanskiy, Y.A.; Talalaev, R.A.; Karpov, S.Y.; Makarov, Y.N.; Bergunde, T.; Lowry, S.A. Detailed Modeling of Metal Organic Vapor Phase Epitaxy of III-V Ternary Compounds in Production-Scale AIX 2400G3 Planetary Reactor. In Fundamental Gas.-Phase and Surface Chemistry of Vapor-Phase Deposition II and Process. Control., Diagnostics and Modeling in Semiconductor Manufacturing IV: Proceedings of the International Symposium; Swihart, M.T., Allendorf, M.D., Meyyappan, M., Eds.; The Electrochemical Society: Atlantic, NJ, USA, 2001; Volume 2001-2013, pp. 292-300.

19. Mountziaris, T.J.; Kalyanasundaram, S.; Ingle, N.K. A reaction-transport model of GaAs growth by metalorganic chemical vapor deposition using trimethyl-gallium and tertiary-butyl-arsine. J. Cryst. Growth 1993, 131, 283-299. [CrossRef]

20. Clayton, A.; Irvine, S. The kinetics of parasitic growth in GaAs MOVPE. J. Cryst. Growth 2007, 300, $277-283$. [CrossRef]

21. Bergunde, T.; Dauelsberg, M.; Kadinski, L.; Makarov, Y.N.; Weyers, M.; Schmitz, D.; Strauch, G.; Jürgensen, H. Heat transfer and mass transport in a multiwafer MOVPE reactor: Modelling and experimental studies. J. Cryst. Growth 1997, 170, 66-71. [CrossRef]

(C) 2020 by the authors. Licensee MDPI, Basel, Switzerland. This article is an open access article distributed under the terms and conditions of the Creative Commons Attribution (CC BY) license (http://creativecommons.org/licenses/by/4.0/). 